\title{
Sports games for people with intellectual disabilities. Institutional analysis of an unusual international configuration.
}

Elise Lantz, $\mathrm{PhD}$ in sport sociology, researcher, Maison des Sciences Sociales du Handicap, Institut Fédératif de Recherche sur le Handicap, INSERM, Paris, France. elise.lantz@gmail.com

Anne Marcellini, Professor, Institute of Sport Sciences (ISSUL), University of Lausanne, Switzerland. anne.marcellini@unil.ch

\begin{abstract}
Today, intellectually disabled athletes can participate in a variety of international sports competitions. For an athlete, access to one or another of these events is possible according to their level of sporting ability or their intellectual capacity, but also depends on their country and the extent to which it hosts International Sports movements. One option for those who have the greatest sporting achievements - and often the greatest intellectual capacity - is to be involved in the competitive circuit of the International Sports Federation for Persons with Intellectual Disability (INAS-FID), organized according to the pyramidal logic of traditional elite sports and in which the ultimate aim is participation in the Paralympic games, a greatly valued perspective that epitomizes a process of de-stigmatization of these athletes. Everyone - including those who cannot attain a high level of sporting ability - can participate in an international sports event and 'play at' being champion by committing to the Special Olympics movement, which offers particular and nonselective sports games, but which does not command the same recognition or the eventual destigmatization.
\end{abstract}

Keywords: International sports events - Paralympic movement - Special Olympics movement International Sports Federation for Persons with Intellectual Disability (INAS) - Sport Union for athletes with Down Syndrome (SUDS) - Sociology. 


\section{Introduction}

Since the end of the 1960s, different organizations aiming to promote and organize sports for people with intellectual disabilities have seen the light of day at the local, national and international level. Their access to sports activities has progressively developed over the last 50 years and today there is a much wider variety of athletes with a form of intellectual disability. Whereas some find it impossible to understand commands or rules, others have simple difficulties in situating themselves in time or space. Some have no sense of competition or even of opposition whereas others train and progress every day, winning championships and dreaming of becoming champions. Moreover, people with only feeble intellectual capacity can achieve important results in sport, because the consequences of limits on intellectual capacity on sporting performance are very variable and depend, amongst other things, on the demands each sport makes on an athlete.

\section{A national experience questioned in its relation with an international one}

In March 2009 in France, the Ministry for Sports recognized as 'top-level' sporting disciplines five sports put forward by the French Federation for Adapted Sport (FFSA), - which brings together sports for athletes with intellectual disability or mental illness - namely athletics, basketball, football, swimming and table tennis. Some 70 athletes of the FFSA thereby acquired the highly desirable official status of top-level athlete and received further intensive training in order to represent their country in international sports competitions. This ministerial recognition came about in a landscape in which international sporting competitions for athletes with intellectual disability were being comprehensively transformed. It is in this context that we have developed a research program on the repercussions of the development of top-level sports for intellectually disabled athletes, which have been supported by the FFSA ${ }^{1}$. Two avenues of research are explored. The first concerns the repercussions of this top-level sport on the athletes at the French centres of the FFSA ${ }^{2}$ with its highly competitive aims (Beldame, Lantz, \& Marcellini, 2016). The second research avenue bears on the repercussions of a top-level sport on sports organizations dedicated specifically to people with intellectual disabilities, on international movements and on national federations, including the FFSA, and the first results of this organizational dimension are being presented here. The purpose of this article is to show, based on the analysis of the different multisport global games that now welcome athletes with intellectual deficiencies, which the organizations and international institutions support and promote it, and according to which rationales.

\section{A method that harmonizes official discourse with concrete practices}

Our methodological approach was determined using different kinds of data. First of all, we established the state of research in the academic literature available for competitive sports for people with intellectual disabilities, which has facilitated our understanding of the present situation against the background of the historical debates held and analyzed since the 1970s. Then, focusing on the particular national case of the FFSA, we researched documents and other written sources on the present and past situation (communiques, internal or external, of the national and International federations, the Federal journal - Sport Adapté Magazine -, official documents relative to criteria of eligibility in different worldwide events, newspaper articles, and Internet sites of the different national and international organizations and federations). In 2014 and 2015 we carried out an interview-based survey during the training programs of Pole France Sport Adapté (a top-level training centre), and had many informal exchanges with management teams and athletes 
concerning the functioning of the international competitive circuit. This data was completed by interviews in 2014 and 2015 with French athletes directly involved in international sport for people with intellectual disabilities.

This data was analysed through two complimentary readings, as René Lourau (1970) once proposed: Analysis of the official and ideological discourses which convey certain kinds of messages, an analysis of practices and concrete ways that give access to other messages to be decoded.

The initial results of our research allow us to present first a description of the four global games currently on the international sports calendar that host events bringing together athletes with intellectual disabilities. After that, we propose an institutional analysis of the associations, federations and sports movements that promote these worldwide sporting events, analysis that shall underscore fundamental differences in the conceptualization and organization of sports of the two entities organizing large-scale events. We will then put forward an initial analysis of a new dissident federation that is currently emerging. Finally, we shall discuss the implantation of these sports movements in different countries and question the possible meanings of this dual international configuration.

\section{A descriptive presentation of the four global sports events featuring sports champions with intellectual disabilities}

The current landscape of global sports competitions in which athletes categorized as intellectually disabled are entitled to participate can be circumscribed by four large-scale international multisport events (Games) ${ }^{3}$, namely Special Olympics World Games, Global Games, Paralympic Games, and anticipating somewhat, as we shall see, the Trisome Games. This landscape is completely new because essential and interlinked changes have come about in recent years.

Indeed, it was only on 21 November 2009 that members of the International Paralympic Committee (IPC) voted to bringing athletes with intellectual disabilities back into the fold of Paralympic competitions ${ }^{4}$. This decision took effect for the London Paralympic Games of 2012. At present, therefore, even though few people know it, the Paralympic Games now welcomes athletes with intellectual disabilities alongside those with motor or visual impairments. In the 2012 London summer games, 118 out of the 4200 Paralympic participants were classified as 'intellectually impaired'. Few were the countries, however, to present athletes with limited intellectual capacity in their Paralympic teams. Of the 160 countries represented in the Paralympic Games, only 36 (22\%) included athletes with intellectual impairment. And their presence was limited, as there were never more than 10 of them on a Paralympic team. In London, they participated in 10 events involving only 3 sports: table tennis (12 participants, in men's and women's singles), swimming (47 participants in three events: 100 meter crawl, 100 meter backstroke, 200 meter freestyle, men and women combined), and athletics (89 participants in 3 events: long jump, shot put and 1500m, men and women combined) (Brittain, 2016). The same events were open to them during the Rio 2016 Paralympic Games.

On a parallel track, the $4^{\text {th }}$ global games, an international competition entirely dedicated to athletes with intellectual disabilities organized by the International Sports Federation for Persons with Intellectual Disability (INAS-FID), were held in 2015 in Ecuador. They brought together 700 athletes with an intellectual disability from 35 countries. The athletes were allowed to compete in nine disciplines (athletics, swimming, table tennis, basketball, cycling, futsal, tennis, taekwondo, rowing). Athletics, swimming, and table tennis also constituted a selection phase for the Paralympic 
Games of Rio in 2016.

With very different dynamics and on a much larger scale, the $14^{\text {th }}$ Special Olympics World Summer Games were held in Los Angeles in 2015 and hosted 6500 athletes. 165 delegations composed solely of athletes with intellectual disabilities participated in these games, which were open to athletes from age 8 (two thirds of them were over $18^{5}$ ). The athletes were allowed to compete in 22 sports - including the three sports included in the Paralympic Games of 2012 - and to participate in 4 demonstration events. Out of the four global games analyzed here, the Special Olympics Games was consequently the event offering the widest range of sports disciplines. The majority of sports in its program are classic Olympic disciplines, but some are not, no longer so, or hope one day to be so. For example, it included Bowling, which hitherto was only a demonstration event at the Paralympic Games, Softball, which ceased to be an Olympic discipline in 2012, and Roller, which has put forward its third candidacy to become for becoming an Olympic discipline by 2020. And so, whereas INAS-FID and IPC include only Olympic disciplines in their global games, Special Olympics provide a chance for a large number of participants to perform in a wide range of sports disciplines.

In addition to these three international multi-sport events open to athletes categorized as having intellectual disabilities, a fourth event, which stands out in this landscape, has only recently come to the fore. Indeed, a subgroup of athletes with intellectual disability, namely those for whom the aetiology underlying their disability is a well-known genetic anomaly, Trisomy 21, recently competed in the Trisome Games, which first took place in Italy in July 2016. The organizers of the event had expected 700 athletes from six continents ${ }^{6}$ and there was no limit on the number of athletes to be registered by country or by sport. These athletes were allowed to compete in different sports events: athletics, futsal, sports gymnastics, judo, swimming, synchronized swimming, tennis and table tennis.

We can see how the existence of these four distinct global games constitute a varied International sports world in which, in a discreet way, invisible to the general public, intellectually disabled athletes can be selected for one or another of these international events. They consequently have more than one way of becoming international champions. In order to better understand this situation, we shall get acquainted with the associations, federations and international sports movements organizing these different global games.

With this in mind, we are about to take a closer look at the history, discourse and modes of organization of the associations, federations and movements involved in these different global games. From the long history of the global Special Olympics since 1968, to the more recent and tumultuous history of the incorporation of the category 'intellectual impairment' in the Paralympic games (1996 and 2000, then 2012), intertwined with that of the Global Games, which started in 2004, and up to the arrival of the first Trisome Games in 2016, we will explore the significance of these different International Games that have taken place in varying socio-historical contexts. Does each event defend a particular definition of an athlete with an intellectual disability or mental illness or of what constitutes a sports champion? Do these different games refer to different social representations of people with intellectual disability or to a different representation of sport, and if so, which?

\section{'Playing at' being a champion? A look at the Games of the Special Olympics movement.}

Historically, the first instance of an associative sports practice for people with intellectual disabilities was organized in 1946 by the Kennedy family, when it set up the Joseph P. Kennedy Jr. 
foundation in memory of their son killed during World War II and dedicated to helping people considered as 'mentally retarded'. In 1962 Eunice Kennedy explained that the orientation of the family foundation towards intellectual disability was connected with the situation of Rosemary, her sister. Rosemary, who was presented as 'mentally retarded', nonetheless accompanied her brothers and sisters in their numerous sports activities until she came of age, at which time she was placed in a Catholic institution ${ }^{7}$. Several versions of her history ${ }^{8}$, which reveal a more complex reality than the official history, can be accessed today (Clifford Larson, 2016). Be that as it may, Eunice Kennedy committed herself to the foundation and began to visit state institutions harboring people with intellectual disabilities. She often spoke of how shocked she was at the terrible hygiene in these establishments and, particularly, by the at-times total absence of activities for the residents. Her reaction to what she had witnessed consisted in a major personal investment in the field of mental retardation, notably in her mission as a consultant for the President's Panel of Mental Retardation in 1962, and above all by organizing activities for children with an intellectual disability.

In 1962 she organized an initial summer sports camp, Camp Shriver, which welcomed 34 children with intellectual disabilities. Its success led her to make it an annual event. More broadly speaking, the foundation financed various organizations dedicated to the creation of similar sports camps in other cities of the United States. These camps were aimed primarily at improving their participants' quality of life, an objective that was reaffirmed during the workshops organized by the Kennedy foundation to promote physical activity for all persons, including those with intellectual disabilities. In collaboration with the city of Chicago, in 1968 the Kennedy foundation organized the First Special Olympics International Games. It then attained momentum outside as well as inside the United States with National Special Olympics movements developing in many countries throughout the world. Today, the organization boasts in its promotional literature of the fact that 170 countries have developed Special Olympics programmes and participate in the Games. It should be specified however, that some teams described as those representing countries in fact correspond to territories (for example, the independent teams of overseas territories such as French Guadeloupe and the British Virgin Islands). This type of representation, which conflates countries and regions by feigning to ignore states, feeds an inflation of numbers aimed at ensuring its supremacy among sports events for people with intellectual disabilities at global level. The Special Olympics global games take place every two years, alternating between winter games and summer games. Until 1991 they almost always took place in the United States, but since then they have been held in another country one out of every two times.

The Special Olympics movement applies the principle of the right to participation for all in its sports events, without restrictions in terms of either incapacity or level of sporting ability. In practice, in each country the coaches recruit the athletes who will participate in the international Games by developing their own selection criteria, which never depend on attainment of a minimum level of sporting achievement. Generally speaking, the criteria refer to constant involvement in the practice of sports: regular training and the fact of participating first in regional and then in national games. To be ruled eligible to take part in the World Games it is also necessary to conform to given expectations pertaining to attitude and behaviour: to have a sporting attitude, to have enough emotional and relational competence to ensure a certain degree of autonomy during lengthy stays overseas. Lastly, some national organizations have recourse to a lottery system to designate those who will compete internationally, a form of random selection representing the ultimate refusal to select on the basis of performance. The prior achievements of athletes, whatever they may have been are taken into account only in order to group the participants according to a homogeneous level of achievement during sports events, in a system of 'divisioning' that aims to give everyone 
a chance to win. This kind of system allows a maximum number of persons to participate in the games and to exhibit and promote wide-ranging diversity in terms of both sporting ability and intellectual capacity.

In this way, even though the games are advertised and known by an appellation seemingly striving evoke the Olympic Games, the underlying logic of the Special Olympics Games is decidedly different insofar as anyone can one day participate in the World Games Special Olympics, whatever their sporting achievement. In a review of the literature on the Special Olympics movement, Storey (2004) lists the authors who have criticized this manner of proceeding. The main critique bears on the allegedly segregated nature of the classification of the athletes as all having an intellectual disability, a categorization that could accentuate the associated stigma (Hourcade, 1989; Wolfensberger, 1995). Some authors have criticized what they consider to be the infantilizing and hyper-protective nature of the movement, notably giving a medal and a hug to each athlete (Fleischer and Zames, 2001). The infantilisation of adults with intellectual disability is perceived by some authors as a widespread form of stigmatization (Giami, Assouly-Picquet, \& Berthier, 1988) and this reproach is levelled at Special Olympics because they are said to treat adults and children in the same way, thereby discrediting themselves. Lastly, the competitive tenor proposed by Special Olympics, which is based on a refusal of selection by achievement, and in which 'everybody wins', is criticized as being exceedingly far removed from the ordinary sports world: 'The Special Olympics set up an artificial environment where the rules are not the same as in integrated settings' (Storey, 2004).

At the individual level, what is the significance of a championship status that is apparently so easy to achieve? Based on a traditional sports model with its logic of performance and pyramidal structure, one could consider the selection method specific to Special Olympics as a sporting simulacrum and assert that it fails to meet the aspirations of all athletes with an intellectual disability. Globally speaking, however, the Special Olympics conception of sport may be characterized as inclusive rather than exclusive (Hassan et al., 2012).

In this model, each and every participant has access to international competition with a real chance of standing on the podium and obtaining a medal. For this to happen, however, it is necessary to 'play the game' of competition by showing total commitment, even if achievementbased results are not eliminatory, as a slogan of the Special Olympics movement clearly indicates: 'Let me win. But if I cannot win, let me be brave in the attempt'. It is through the commitment of athletes to this rationale, due to a degree of autonomy - and, above all, to significant behavioural control - that their participation in this type of sports game is authorized. The Special Olympics Games sheds light on the varied levels of intellectual capacity of these athletes as a recognition of human diversity, which is accepted and respected, with each participant being able to 'play at' being champion.

Given their disengagement with regard to achievement, it can seem surprising that Special Olympics has enjoyed the recognition of the International Olympic Committee (IOC) since 1988 and is allowed to use the term Olympic (adjective whose use has provoked numerous tensions in the world of sports (Ruffie \& Ferez, 2013). Brittain (2009) has described the conditions under which this use was finally accepted. At first, the organizers of Special Olympics simply requested to use the term for the first Special Olympics Games of Chicago, and are said to have received only a verbal agreement for such use from the American Olympic Committee for 1966 and 1967, with the implicit understanding that it would cease thereafter. So it was that use of the adjective 'Olympic' was at once authorized and restricted in time and space. Once the name was adopted and put into circulation, however, requests for restrictions are said to have gone unheeded by Special Olympics. Finally, in 1988, tensions were calmed when the IOC officially recognized Special 
Olympics and granted it the right to use the term 'Olympic' indefinitely. 'It is likely that a combination of the influential political and economic power of the Kennedys combined with the massively influential role the Los Angeles Olympic Games and the part corporate sponsorship had in saving the Olympic movement from financial ruin, played key roles in this' (Brittain, 2009). But above and beyond the economic and political importance of the Kennedys and of the United States, it is likely that in 1988 the IOC considered that this movement offered a very different sporting practice to athletes it might have deemed incapable of participating in classical sports competitions, a practice based on a reordering of the Olympic pyramid but that did not call existing pyramidal functioning into question. At the end of the 1980s, however, new social forces expressed another vision of sport for people with an intellectual disability.

\section{'Being' a champion? A look at the games of the Paralympic Circuit.}

Indeed, parallel to with the Special Olympics movement, other international sports movements and federations were set up according to a more classic sporting logic, incorporating pyramidal selection, competition and the privileging of achievement. It was in 1986 in the Netherlands that the International Sports Federation for Persons with Mental Handicap ${ }^{9}$ (INAS-FMH) was set up to promote the participation of athletes with intellectual disabilities in international top-level sports. From its inception INAS has been a member of the International Coordinating Committee (which became the International Paralympic Committee (IPC) in 1989), and its aim has been to advocate and progressively coordinate the participation of intellectually disabled athletes in Paralympic Games.

\section{Sporting achievements and intellectual disability?}

In 1989 this International Federation organized its ' 1 st World Games for Athletes with an Intellectual Disability' in Sweden. In 1992, Games specifically aimed at people with intellectual impairment were recognized by the IPC and organized in Madrid just after the Paralympic Games of Barcelona. In 1996 that athletes with intellectual disability were included for the first time in the Paralympic games, at Atlanta. A greater role was reserved for them in the games of Sydney in 2000, a Paralympiad during which the rules were severely breached ${ }^{10}$, which led to the suspension until 2009 of all events aimed at athletes with intellectual disability. It was in this context that INAS decided to organize new worldwide games called Global Games. Since 2004 these games have followed a staggered agenda in relation to the Paralympic calendar, and the fourth Global Games were held in Ecuador in 2015.

Whether we are dealing with Global Games organized by INAS or the Paralympic Games, these events adopt a classical pyramidal sporting logic in which both INAS and IPC strongly believe. The Paralympic Games are at the top of the pyramid, as the Global Games can, for certain sports, constitute a qualifying event for the Paralympic Games. In order to participate in the INAS or IPC games, athletes must attain a minimum level of achievement to be selected, and they can only compete in one category, whatever their intellectual capacity. The result is that a very small number of athletes with intellectual disability make it to international competitions, only the greatest achievers from a sporting point of view, and that those selected are most often (but not always) those with the least intellectual disability. For them, and only for them, specialized sports federations in different countries provide top-level training facilities allowing them to progress. This dynamic is often sustained by belief in the educability of people with intellectual disability and by the conviction that these people have unsuspected capacities for development, belief that 
can serve as a self-fulfilling prophecy (Beldame and al.). In the dominant sports logic, these people can then be qualified as 'true champions'.

Though it takes Olympics as a model, the Paralympic movement differentiates itself. The Olympic ethic embodies an economy of corporal difference (Liotard, 2004). The principles of categorization by age, gender or weight according to the disciplines, serve to 'neutralise anatomical heterogeneities' for each event and consequently offer a competition that remains equitable and of unpredictable outcome, which is key to the emulation inherent in competitive sports. Liotard shows that this process engenders 'a segregation based on the strict partitioning of differences', with unequal access to different disciplines according to the anatomy of the athletes (id.). The Paralympic model differentiates itself from the limit imposed by the Olympic model through its seeking to render sports events accessible to athletes with the most varied anatomies and functional capacities. Their window of opportunity has been made possible by a complex and progressively developed system for classifying athletes. The system is specific to each sport and based on criteria of impairment and task-oriented functionality that help to maintain an equitable basis and to show 'the sportive combination of bodily differences' (Marcellini \& Lantz, 2014). However, as far as athletes with intellectual disabilities are concerned, it is not always easy to appreciate the limits to their intellectual capacities and the embarrassments and disadvantages they occasion in their sporting performances. As a consequence, in order to ensure equal chances of winning among athletes with intellectual disabilities, one has to think, evaluate and classify the limits in intellectual capacity affecting sporting achievement, which is perhaps more problematical than in cases motor or visual impairment. What preoccupies the sports world to an even greater extent is the risk of conceptual confusion between able-bodied athletes and Paralympic athletes.

At the Winter Paralympic Games of Berlin in 1994, where two demonstration events for athletes with intellectual disabilities took place, the idea of the creation of categories specific to them caused unease among other Paralympic athletes. Howe (2008) observed that the non-initiated took time to make a distinction between Paralympic Games and the Special Olympics games. 'Traditional' Paralympic athletes appeared averse to the arrival in the Paralympic movement of athletes with intellectual disabilities, whose stigma is much stronger than that borne by athletes with physical or sensory disabilities. For them, the Paralympics is the story of different bodies rather than different minds (id.) During a radio debate ${ }^{11}$ bringing together a number of Paralympic athletes, they questioned the need to set up a Paralympic category for athletes without either physical or sensory disability. They suggested that athletes with small intellectual disabilities and a clear sense of competition compete with ordinary, able-bodied athletes. In this way, reluctance to recognize athletes with intellectual disabilities as part of the Paralympic Games was first conveyed by Paralympic athletes themselves; even greater reluctance, however, arose from officials in the Paralympic organization.

\section{Eligibility and classification of athletes with an intellectual disability}

Intellectual disability, which is not a stable category, is difficult to evaluate. If one accepts the fact that there is a difference between an able-bodied athlete and an intellectually disabled athlete and that in the name of equality in sports a specific category has to be set up for athletes with intellectual disabilities in which they have a chance to win, one still has to prove that the athlete legitimately benefits from being thereby categorized. However, establishment of proof is hardly simple. For example, during the 2000 Sydney games, the Spanish basketball team in the 'intellectual impairment' category won the gold medal. A few weeks later, a scandal broke out when one of the team's players, who was also a journalist, held a press conference to denounce the scam in which 
he had taken part as had the 10 other members of the team of 12 who were not intellectually disabled. This announcement exposed massive long-term fraud committed by the Spanish team, and not only in basketball, when able-bodied athletes were enlisted to boost the country's performances (Brittain, 2009).

The works by Brittain $(2009,152)$ show that the main player suspected of organizing the fraud, Fernando Martin Vicente, had started off by denouncing the confession of the journalist-athlete as the lies of a 'handicapped person who had gone mad'. This association between madness and intellectual impairment, which reinforces existing stereotypes (Giami and al., 1988), stigmatizes disabled athletes even more. A complete enquiry by the Spanish Paralympic Committee revealed the prolonged worldwide fraud for which Fernando Martin Vicente wound up assuming responsibility. He was at that time Vice-president of the Spanish Paralympic Committee, President for the Spanish federation for Sports for the intellectually disabled, and also, at the international level, President of INAS-FID and member of the Paralympic executive committee (Brittain, 2009, 154). Deception was thus found to permeate at the heart of the sports organization for the intellectually handicapped, and its exposure led to the expulsion from INAS-FID not only of Fernando Martin Vicente, but also of all of those who had voted in favor of his accession to the presidency of INAS-FID. The IPC also decided to collectively suspend all of the INAS-FID athletes and to bar them from any Paralympic participation. This drastic reaction, which excluded all members of the Federation rather than just those guilty of fraud, and similarly expelled people with intellectual disability for a deception dreamt up and organized by the institutional promoters of the sport, revealed the malaise already poisoning relations between the IPC and INAS-FID. The suspension was nonetheless temporary and was associated with the introduction of a working committee bringing together INAS (with a new team) and the IPC in view of reaching a new agreement concerning eligibility procedures through which more precise criteria for measuring intellectual disability would be identified. To this day, these criteria of eligibility are independent of a given sport and do not take into account task requirements, as a sheerly functional logic would demand $^{12}$. It was while validating these procedures that a vote taken during the general meeting of the IPC in Kuala Lumpur in Malaysia in 2009 authorized the reintroduction of an 'intellectual impairment' category in the Paralympic Games. Although the president of the IPC, Philip Craven, hailed this achievement, which he considered as 'the outcome of a unique and excellent cooperation between sports governance and the scientific community', the exceedingly tight vote (63 for, 53 against and 7 abstentions) underscored the misgivings of a sizable number of IPC members. Moreover, the vote to once again welcome athletes with an intellectual disability into the Paralympic movement does not seem to have completely calmed the controversy. While 244 athletes with intellectual disability had participated in Sydney 2000, only 118 were present in London 2012, and basketball - focus of the fraud of 2000- was no longer on the program either in 2012 or in 2016.

And so, in order to compete, today's athletes have to declare and demonstrate what differentiates them from able-bodied athletes, namely their intellectual disability. Burns, in an article on this topic, and Sebastiano d'Ayala Valva, in his film 'Adapté' about top FFSA basketball players, both underline the importance for athletes and their paradoxical desire to be included in a highly stigmatized category, that of intellectual disabilities: 'And then you see the words 'intellectual disability' and they are attached to your name. It feels like the whole room fills with sunlight, you can see your future set out before you, people congratulating you, international travel, getting awards, meeting new people... it feels like your life is now full of opportunity.' (Burns, 2012). This strange role reversal is all the more singular given the fact that in order to observe the rules pertaining to competitiveness, the persons in charge of top-level teams are compelled to recruit 
athletes from classic sports clubs who happen to have intellectual difficulties and who may only at that time find out that they might belong to a category called 'intellectually impaired', through which they can benefit from opportunities in sports.

It should be noted that the important work of developing viable procedures of eligibility designed to incorporate athletes with an intellectual disability in the Paralympic games has yet to be accompanied by wider reflection on the diversified character of these athletes. In each sport there exists a single category of athlete called 'intellectually impaired' ${ }^{13}$ covering those with the greatest sporting achievements regardless of the magnitude of their intellectual difficulties. In this way, pyramidal logic propels young athletes with a very similar profile into the Paralympic Games: long-standing sporting experience, looser restrictions on intellectual disabilities, and undoubted capacity for behavioural self-control, all associated with considerable ability to train intensively.

\section{Champions with a verifiable biological identity? A look at the emergence of the Trisome Games}

Within the institutional configuration that connects INAS and the IPC, a particular group has recently set itself apart through the creation of a new international multi-sport Federation: Sport Union for athletes with Down Syndrome (SUDS), which bases itself on the aetiology of a specific form of intellectual impairment, Trisomy 21.

Different international associations specifically set up for athletes with Down syndrome, the Down Syndrome International Swimming Organization created prior to 2008, the International Athletic Association for Persons with Down Syndrome created in 2009, as well as international associations for football and gymnastics, came together in 2012 in Terceira in the Portuguese Azores and set up a Sport Union for Athletes with Down's syndrome. Other international associations working on Trisomy 21 have since joined this union, notably those for table tennis, judo and skiing.

In its promotional literature ${ }^{14}$ the Union emphasizes the athletic abilities of people with Down syndrome and the possibilities they have to become champions, all the while affirming its devotion to Olympic and Paralympic ideals. The Union defends its idea that Down syndrome people have a specific disadvantage as they have physiological as well as intellectual deficiencies, which are not taken into account in sports classifications of people with intellectual disability. It is consequently in the name of 'fair and equal opportunity to be successful' that the union wishes to act. As of 2015 SUDS had two main aims: to petition the IPC for the creation of a Paralympic category 'trisomy 21', and to organize the first Trisome Games, which indeed took place in July 2016.

SUDS has no wish to replace international sports associations dedicated to their respective sports but rather stresses its role as an interlocutor with the IPC, thereby reiterating an initiative previously taken by the Down's Syndrome International Swimming Organization (DSISO). In 2008 the DSISO president, who would become the SUDS president at its creation, asked the IPC to set up a specific Paralympic category for athletes with Down syndrome. His request was refused for the reason that the IPC classified athletes in one category or another according to their disability (functional classification) and not on the basis of the aetiology of their disability. The IPC thereby asserted its opposition to a medical or aetiological classification of athletes, and it repositioned people with Down syndrome as athletes eligible for the 'intellectual impairment' category who would be selected if they achieved the minimum performance level required. In addition, on this occasion the IPC confirmed that INAS-FID was the only international sports federation recognized by the IPC for athletes with an intellectual disability, including those with Down syndrome ${ }^{15}$. It is 
important to add that this exchange between DSISO and IPC took place at a time when the new eligibility procedures for athletes with intellectual disability had yet to be endorsed by the IPC, and when there consequently existed no Paralympic category for these athletes.

The organization of SUDS in 2012 had as its objective to attempt a new approach to the IPC, following avenues of development that the Paralympic Committee were likely to have recommended $^{16}$. In 2015, however, relations between SUDS and IPC remained tense. In February the Union posted on its social network that athletes with Down syndrome would participate in the European Youth Paralympic games reserved for those under twenty ${ }^{17}$. This announcement was contradicted by a 6 March 2015 message in which the organizers of the games ruled out any specific category for athletes with Down syndrome. This decision to annul may have been taken under threat from the IPC of cancelling the European Youth Paralympic Games ${ }^{18}$.

This reaction of the IPC to the SUDS project of categorizing trisomy 21 can be associated with the peculiar way in which competitions function in SUDS and its associations. There is no selection system taking sporting ability into account, and athletes can compete in all sports after a single registration. Nor is there a limitation on the number of participants by country. These elements bring SUDS close to the functioning of Special Olympics. In addition, the registration procedures for the Trisome Games, posted at the beginning of 2016, specify two forms of control. One is related to anti-doping tests and seems intent on confirming the sporting nature of the organization. The other, entitled 'necessary evidence for the confirmation of Down's syndrome', imposes on the athlete the obligation of bringing biological proof of their trisomy 21 or their trisomy 21 Mosaic as well as their willingness to eventually submit to a 'cytogenic analysis' ${ }^{19}$ (at their own expense) if the Union were to have doubts about the trisomy of the athlete.

It is clear enough that the Sports Union for Down's syndrome is a dissident organization in the INAS, in that it questions sports classification based on limits to intellectual capacity, advocating a different type of classification based on the biological aetiology of the intellectual disability, in this case a chromosome anomaly. This logic of classification, what Rabinow (1996) calls biosociality, does not seem compatible with the classificatory logic of the IPC, which is based on the construction of categories of functional equivalence rather than biological identity. Briefly sketched, this is the history of the two models that have structured International sport for people with intellectual disabilities through two formalized circuits, the historical model, Special Olympics, and a more recent model that emerged at the end of the 1980s and grafted itself onto, a Paralympic movement, which up until then had been reserved for athletes with motor or visual impairments. In addition to this organization of two large-scale movements espousing very different sports models, there has emerged a new dissident tendency drawing on considerations of bio-sociality hitherto lacking in sports movements. This unusual international configuration constitutes the institutional formation of the representational conflicts with which we shall conclude.

\section{Two large international competitive events and some conflicts of representation}

The two movements - Special Olympics and the Paralympics - have a different status in each country. In France, the French Federation for Adaptive Sports (FFSA) has an almost exclusive monopoly in catering for people with intellectual disability or mental illness, whether with respect to recreational or competitive sport. At the international level it is a protagonist in the Paralympic Games and also participates in the international events of SUDS ${ }^{20}$. Special Olympics plays only a minor role in France, where it is in competition and at times outright conflict, with the Paralympic movement. 
In some English-speaking countries organizations affiliated to both movements are present and seem to collaborate. This is the case in Australia (Jobling, Jobling, \& Fitzgerald, 2008) and in Great Britain. In Switzerland and Italy, Special Olympics is the only international sports event for intellectually disabled athletes while the United States, Germany and Canada participated only minimally in the Paralympics of 2000; in those countries, the influence of Special Olympics is preponderant $^{21}$.

How should we understand the different weight assigned to these two events have in different countries? Should it be understood from the angle of cultural difference, linked to the different histories and social representations of people with intellectual disabilities in their respective countries? Indeed, promotion in the Paralympics both of athletes who in their normative behaviour and sporting achievements show a troubling closeness to able-bodied athletes, and of athletes forever called kids who are rewarded for their participation by a 'hug' during the Special Olympics events, tend to show very different underlying conceptions of sport for people with intellectual disabilities. Whereas the former propose a 'serious' form of sport that categorizes and hierarchizes, selecting and ordering bodies and minds according to a logic of sportivization (Suchet, 2001) that produces true athletes, the latter proposes a 'pretend' and playful form of sport, which is a pretext for more general participation and uplift, the model having been inherited from the charitable Kennedy family framework and kept functioning along the same lines.

These two sports movements contribute to the mediatisation of intellectually disabled athletes and distribute multiple images, from excellence in sports to infantile scenarios. One would have thought that Paralympic athletes would lose their stigma and that the stigma would instead be attached to the far larger number of lesser-performing athletes, including those participating in the Special Olympics games. However, it should be noted that Special Olympics is the only organization which, in international sporting events, offers events combining considerable differences in intellectual capacity. Indeed, the Paralympic institution has not yet organized a classification of athletes that would permit participation of those who are seriously intellectually disabled. Given this fact, the different debates outlined in this paper remain on-going.

The recent emergence of SUDS, the union of international sports associations that rely on a particular aetiology of intellectual disability, has rekindled the aforementioned debates and generated some tension; doesn't this latest development look strangely like a return to the medical vision of disability? A more detailed monograph on the sports union built around Down syndrome and of the key protagonists, consequently presents itself as a most exciting avenue for research.

\section{Notes}

1. This research was conducted in the framework of a scientific collaboration between the Santesih Laboratory of the University of Montpellier (EA 4614) and the 'Study and Research' section of the French Federation of Adapted Sport, with financial aid from the latter. The analyses presented in this paper do not necessarily reflect the viewpoint of the FFSA.

2. The 'French centres' are training and management mechanisms for top-level and promising athletes which can be organized in different ways depending on sports federations.

3. It is important to specify here that we are talking about multi-sport events because there are numerous other global sports events for each discipline, such as, for example, the world Paralympic athletics Championships. 
4. The first decision as to the integration of this category of athletes into the Paralympic Games dates from 1989, when the IPC was founded.

5. Website specialolympics.org, section "Who Are Our Athletes?"

6. Website “www.su-ds.org/2016-trisome-games", $1^{\text {st }}$ May 2016.

7. Hope For Retarded Children. Eunice Kennedy. The Saturday Evening post, 22 September 1962.

8. Rosemary, the last secret of the Kennedys. Le Monde, 7 april 2009.

9. Initially called INAS-FMH, International Sports Federation for Persons with a Mental Handicap, the Federation was renamed INAS-FID, International Sports Federation for Persons with Intellectual Disability in 1994.

10. As we will develop below.

11. Debate BBC 1994 - 'Disability for Dollars'. Online.

12. Indeed, when an athlete is already accepted as eligible by INAS for one sport but wishes to compete in another sport, they only have to fill in a simplified questionnaire. www.inas.org/memberservices/eligibility-and-classification.

13. The specific categories for intellectual disability recognized by the IPC are: swimming classification S/SB14, athletics classification T20/F20, table tennis classification 11.

14. Document "Su-Ds Presentation" is available on the website of the Federation.

15. Official letter of the IPC to DSISO, 28 April 2008.

16. Website IAADS, section “about us”, May 2016.

17. Facebook page of Su-ds, 26 February 2015 and 6 March 2015.

18. The official document of the presentation of the European Youth Paralympic Games, which dates from January 2015, clearly includes the « Down syndrome » category for each sport.

19. Su-Ds 'registration pack' for the Trisome Games 2016.

20. Indeed, a team of eight swimmers went to the world championship of the Down Syndrome International Swimming Organisation in 2014, and French 'Trisomy 21' teams have been created for table tennis and swimming (source: document produced by the FFSA following the world Championships of DSIDO, November 2014, Mexico).

21. On this subject, see Jobling et al., 2008; the situation has not really changed since then because during the Paralympic Games of London in 2012, in the category 'intellectual impairment', there were one American, two Germans and three Canadians.

\section{References}

Beldame, Yann, Elise Lantz and Anne Marcellini. "Expériences et effets biographiques du sport adapté de haut-niveau. Étude de trajectoires sportives et professionnelles d'athlètes catégorisés comme ayant des incapacités intellectuelles,” ALTER - European Journal of Disability Research 10(3) (2016): 248-262.

Brittain, Ian. The Paralympic Games explained. London: Routledge, 2010.

Burns, Jan. "Falling through the rabbit hole: elite sports and people with intellectual disabilities", Journal of Critical Psychology Counselling and Psychotherapy 11(1) (2012): 56-63.

Clifford, Larson K. Rosemary, l'enfant que l'on cachait, Paris: Les Arènes, 2016.

Fleischer, Doris Z. and Frieda Zames. The disability rights movement: from charity to confrontation. Philadelphia: Temple University Press, 2001.

Giami, Alain, Colette Assouly-Piquet and Francette Berthier. La figure fondamentale du handicap: représentations et figures fantasmatiques, Rapport de recherche, Paris: MIRE-GERAL (1988): 131.

Hassan, David, Sandra Dowling, Roy McConkey and Sabine Menke. "The inclusion of people with intellectual disabilities in team sports: lessons from the Youth Unified Sports programme of Special Olympics,” Sport in Society 15(9) (2012): 1275-1290. 
Hourcade, Jean-Jacques. "Special Olympics: a review and critical analysis," Therapeutic Recreation Journal 23(1) (1989): 58-65.

Howe, David. The Cultural Politics of the Paralympic Movement; through the anthropological lens. London: Routledge, 2008.

Jobling, Anne, Ian Jobling and Hayley Fitzgerald. "The inclusion and exclusion of athletes with an intellectual disability”. In Benchmark Games. The Sydney 2000 Paralympic Games, edited by Richard Cashman and Simon Darcy, Pertersham: Walla Walla Press, 2008.

Liotard, Philippe. "L'éthique sportive : une morale de la soumission?”. In Le sport et ses valeurs, edited by Michaël Attali, 117-156. Paris: La Dispute, 2004.

Lourau, René. L'analyse institutionnelle. Paris: Éditions de Minuit, 1970.

Marcellini, Anne and Elise Lantz, “Compétition et classification paralympique. Une nouvelle conception de l'équité sportive ?”. In Corps, Sport, Handicaps, Tome 2, Le mouvement handisport au XXIe siècle Lectures sociologiques, edited by Anne Marcellini and Gaël Villoing, 61-74. Paris: Téraèdre, 2014.

Ruffié, Sébastien and Sylvain Ferez. Corps, sport, handicaps, Tome 1, L'institutionnalisation du mouvement handisport (1954-2008). Paris: Téraèdre, 2013.

Rabinow, Paul. Artificiality and Enlightenment: From Sociobiology to Biosociality. Essays on the anthropology of reason. Princeton: Princeton University Press, 1996.

Storey, Keith. "The Case against the Special Olympics,” Journal of Disability Policy Studies 15(1) (2004): 35-42.

Suchet, André. "La sportivisation des pratiques dites nouvelles. Contribution à une revue de la littérature française en sociologie du sport,” Aspects sociologiques, 18(1) (2001): .

Wolfensberger, Wolf. "Of "normalization" lifestyles, the Special Olympics, deinstitutionalization, mainstreaming, integration, and cabbages and kings,” Mental Retardation 33(2) (1995): 128-131. 